\title{
Green method for efficient PdNPs deposition on carbon carrier in the microreactor system
}

\author{
Magdalena Luty-Błocho (D) Marek Wojnicki • \\ Grzegorz Włoch $\cdot$ Krzysztof Fitzner
}

Received: 26 March 2018 / Accepted: 23 August 2018/Published online: 7 September 2018

(C) The Author(s) 2018

\begin{abstract}
The synthesis of palladium nanoparticles and conditions of their deposition on active carbon fibers in the microreactor was described. All processes related with metal ion reduction, nucleation, and autocatalytic growth of particles as well as their deposition were carried out in the microreactor in only one cycle. Synthesis of palladium nanoparticles was carried out under different conditions, i.e., changing the initial concentration of metal ions and the reductant, at $40{ }^{\circ} \mathrm{C}$. Depending on the conditions imposed, the nanoparticles of different size (hydrodynamic radius change from 12 to $37 \mathrm{~nm}$ ) and shape (spherical, cube, pyramid) were obtained. It was also shown that flow conditions allow for much more efficient $\mathrm{Pd}$ deposition on active carbon fibers than the process carried out in the batch. It was observed that for concentrations of $\mathrm{Pd}(\mathrm{II})$ ions higher than $0.2 \mathrm{mM}$, the degree of fiber surface coverage increased significantly in comparison with the batch process.
\end{abstract}

Keywords PdNP synthesis - Active carbon fibers · Catalyst $\cdot$ Microreactor Continuous synthesis .

Nanostructured catalyst

Electronic supplementary material The online version of this article (https://doi.org/10.1007/s11051-018-4337-9) contains supplementary material, which is available to authorized users.

M. Luty-Błocho $(\square) \cdot$ M. Wojnicki $\cdot$ G. Włoch $\cdot$ K. Fitzner Faculty of Non-Ferrous Metals, AGH University of Science and Technology, Al. A. Mickiewicza 30, 30-059 Krakow, Poland e-mail: mlb@agh.edu.pl

\section{Introduction}

Due to their unique physicochemical properties and depending on their morphology, palladium nanoparticles (PdNPs) may find an application in catalysis (Das et al. 2015; Gómez-Martínez et al. 2015; Lemo et al. 2006; Li et al. 2014; Magdesieva et al. 2014; Ncube et al. 2015; Reyes-Rios and García 2012; Shen et al. 2011), sensors (Chen et al. 2016; Choi et al. 2015; Cincotto et al. 2017; Gupta et al. 2014), fuel cell (Brandão et al. 2010; Ohara et al. 2009), and hydrogen storage (Dündar-Tekkaya and Yürüm 2016; Fang et al. 2015; Faye et al. 2017; Ma et al. 2015; Nair et al. 2015; Pang and Li 2016; Thanh et al. 2016; Viswanathan 2017).

Our attention was attracted by the process of catalysis, which uses $73.5 \%$ of the world's palladium production (https://www.advantagefutures.com/outlook-2016 ). It also seems that the demand for palladium will grow due to the rapid development of the industry. It is known that the best catalytic properties are associated with nanoparticles size, due to high surface to volume ratio. However, for many systems production, heterogeneous catalyst, even with excellent catalytic properties, is not enough. It is known that an equally important feature of catalysts is the ease of removing them from the gas or liquid-phase reaction mixture, as well as their ability to be reused. For the first purpose, catalyst supports like active carbon, $\mathrm{Al}_{2} \mathrm{O}_{3}, \mathrm{TiO}_{2}$, and $\mathrm{SiO}_{2}$ are applied. The choice of these materials consists in their inert behavior in various environments. The process of catalyst arrangement on a support can be 
achieved using precipitation and impregnation method (Munnik et al. 2015; State et al. 2017), conducted in a batch reactor. Precipitation techniques induce metal particle growth by supersaturation of the precursor solution, resulting in metal particle nucleation and growth. This can be done in conjunction with the formation of the support (coprecipitation) or on an existing support (precipitation deposition). Impregnation techniques bring the support into contact with a precursor solution. Low loadings of noble metals on a catalyst carrier are achieved by adsorption of the metal precursor by surface groups existing on the support, after which excess precursor is removed. Otherwise (higher loadings), the washing step is skipped and the support is dried directly so that whole amount of the precursor ends up on the support (impregnation and drying). Catalytic particles may also be formed in the colloidal route, in which metal precursor is reduced using reductant and the formed particles size and shape can be additionally controlled using stabilizers or ligands. After that, the formed particles are deposited on the support. The vapor deposition includes metal atoms, clusters, or organic substances in the gaseous phase, that selectively react with carrier surface groups (Munnik et al. 2015).

Such a process is multistage, takes some time, and requires further product purification. Thus, it is desirable to develop a relatively cheap and simple technique of particle production, which will eliminate these disadvantages and shorten the time of catalyst preparation. One of the ways to improve the process is its transfer from macroscale to microscale, which can be realized in microsystems (Ehrfeld et al. 2000). The term microsystem should be understood as a system composed of microreactors, mixers, microcapillaries, and pumps. Most advantages of the microreactor result from its small channel dimensions (high surface to volume ratio), which allow for fast reagents mixing, very rapid heat and mass transfer, controlled residence time of reagents in the microchannel realized by, e.g., flow rate and dimension of the channels, low reagent consumption, and a small amount of generated waste. Besides, the microsystem is flexible, because it allows for the connection of many reactors together, if a process requires a lot of reagents. It can also be applied to multistage processes, which require different conditions each. The microsystem allows the process intensification (Yao et al. 2015), and may find the application in such areas as biodiesel production (Madhawan et al. 2018), catalysis (Tanimu et al. 2017), green and sustainable synthesis, nanoparticle synthesis (Wojnicki et al. 2015; Zhao et al. 2011), and their deposition on the active carbon (Luty-Błocho et al. 2013) as well as metal particle synthesis in aqueous solution even at temperatures above $100{ }^{\circ} \mathrm{C}$ (Luty-Błocho et al. 2014).

In this work, we have explored the conditions necessary to obtain PdNPs in one-step continuous process, and their deposition on carbon fibers.

\section{Experiment}

\section{Materials}

Precursor of metallic palladium The basic solution of $\mathrm{Pd}(\mathrm{II})$ ions was $0.1127 \mathrm{M}$ of $\left[\mathrm{PdCl}_{4}\right]^{2}$. The stock solution was prepared by dissolving of $14.8846 \mathrm{~g} \mathrm{Pd}$ (pure 99.99; Mennica Państwowa, Poland) in an aqua regia (mixture of concentrated hydrochloric and nitric acid in volume ratio 3:1, POCH; Gliwice, Poland) repeated evaporation to dryness and dilution in deionized water repeated twice (Wojnicki et al. 2016).

Reductant L-ascorbic acid (Sigma-Aldrich, Germany) in proper amount was dissolved to obtain the desired concentration of the reductant. All reagents used in experiments were pure grade.

Active carbon fibers as PdNP carrier In order to prepare nanoparticle carrier, the commercially available carbon mate was applied. Activation of the carbon fiber surface was made according to the procedure described previously (Muszynski et al. 2008). For this purpose, $2.5 \mathrm{~g}$ of carbon fibers was added to the mixture of sulfuric acid $(44 \mathrm{~mL})$ and nitric acid $(29 \mathrm{~mL})$. Agitation of the mixture was carried out very carefully in a fume cupboard over $30 \mathrm{~min}$, where potassium chlorate was added. Then, the mixture was stirred under a fume hood for 5 days until the stripping of "yellow gases" came from nitric dioxide. After this time, the mixture changed the color from yellow to blue and the obtained suspension was diluted with 21 of deionized water and then filtered. The precipitate was additionally rinsed with $250 \mathrm{ml}$ of $5 \%$ solution of hydrochloric acid. Finally, the carbon fibers were rinsed twice with deionized water to remove excess of $\mathrm{HCl}$. The filtered carbon fibers were dried at $80{ }^{\circ} \mathrm{C}$ for approximately $12 \mathrm{~h}$. In all experiments, $0.01 \mathrm{~g}$ of active carbon fibers was used. 
Sample analysis

Spectrophotometer UV-Vis (Shimadzu, Japan), working in the wavelength range of 190-900 nm, was used to register the kinetics of the reaction and to analyze plasmon resonance, respectively. In order to measure the size and size distribution of the obtained particles, Nanozetasizer Nano-ZS (Malvern, UK) was used. The microstructure observations were performed using scanning electron microscopy (SEM; Hitachi U-70, Japan).

Sample preparation for spectrum analysis The samples with the PdNPs were analyzed spectrophotometrically (plasmon) $10 \mathrm{~min}$ after collection of about $2 \mathrm{ml}$ of the solution. The sample of colloidal palladium collected during experiments was examined twice (before and after passing the solution with PdNPs through the filter with ACF).

Sample preparation for dynamic light scattering analysis Directly after plasmon registration, the solution with colloidal palladium was analyzed (size and size distribution) using dynamic light scattering (DLS) (Nanozetasizer Nano-ZS, Malvern, UK) method.

Sample preparation for microscope analysis Immediately after collection of PdNPs for spectrum analysis, i.e., $1 \mathrm{~min}$, after collecting the required volume for spectra and DLS analysis, the Pd/ACF was removed from the filter and dried at $50{ }^{\circ} \mathrm{C}$ for $4 \mathrm{~h}$. After this time, the catalyst was cooled down, and was glued by Nafion to SEM sampler and dried again at room temperature for at least $12 \mathrm{~h}$. The prepared sample was analyzed with the use of SEM microscope.

\section{Experimental setup}

The palladium nanoparticle synthesis was conducted in the flow microreactor (Syrris, UK) with total volume $250 \mu \mathrm{l}$ (mixing zone parameters: channel deep $250 \mu \mathrm{m}$, wide $300 \mu \mathrm{m}$; reacting zone: deep $250 \mu \mathrm{m}$, wide $400 \mu \mathrm{m}$, and length $2509 \mathrm{~mm}$; Fig. 1). The microreactor was coupled with two syringe pumps operating at a flow rate from 0.001 to $10 \mathrm{ml} / \mathrm{min}$, and a Teflon capillary that led the solution from the microreactor to the sampler. The microreactor contains two inputs: one for an aqueous solutions of L-ascorbic acid and another one for $\operatorname{Pd}(\mathrm{II})$ ions. Reagents are mixed in a micromixer and then directed to the reacting channel where the reduction reaction, the nucleation, and subsequent growth of palladium nanoparticles take place. The microreactor system is shown in Fig. 1.

As a result of the synthesis conducted in a microflow, the palladium nanoparticles were obtained and deposited on a carbon carrier. Synthesized nanoparticles were analyzed spectrophotometrically. The morphology and size distribution of synthesized materials were analyzed using DLS method and SEM.

Experimental conditions

Synthesis of palladium nanoparticles was carried out under different conditions shown in Table 1.

Relation between kinetic study and flow parameters

The processes of reduction and particle deposition on carbon support in the flow require kinetic data which are necessary to flow parameter calculation. For this purpose, we used kinetic data given in our previous work. Based on that previous study (Wojnicki et al. 2016), the optimal resistance time $t_{0}$ and total flow rate (i.e., $6.0 \mathrm{ml} /$ $\mathrm{min}$ ) in the microreactor were established (see Supplementary materials) from the obtained sigmoidal curves related to slow nucleation and fast autocatalytic growth. Constant temperature for nanoparticle synthesis in the flow was also selected $\left(40^{\circ} \mathrm{C}\right)$.

\section{Results and discussion}

In order to optimize the size and the size distribution of PdNPs, two variables can be adjusted at constant temperature, i.e., the concentrations of $\mathrm{Pd}(\mathrm{II})$ ions and the reductant.

The influence of initial concentration of metal precursor

The process of PdNP synthesis was carried out at different initial concentration of metal precursor in the range of $0.05-0.4 \mathrm{mM}$. To keep the constant excess of the reductant, the molar ratio of $\mathrm{Pd}(\mathrm{II})$ ions to ascorbic acid was maintained 1:2 (Table 2) in the experiment. As a result of the synthesis conducted in the microreactor, colloidal palladium having different color was obtained (Fig. 2a-e). The change of color from light yellow which is typical 

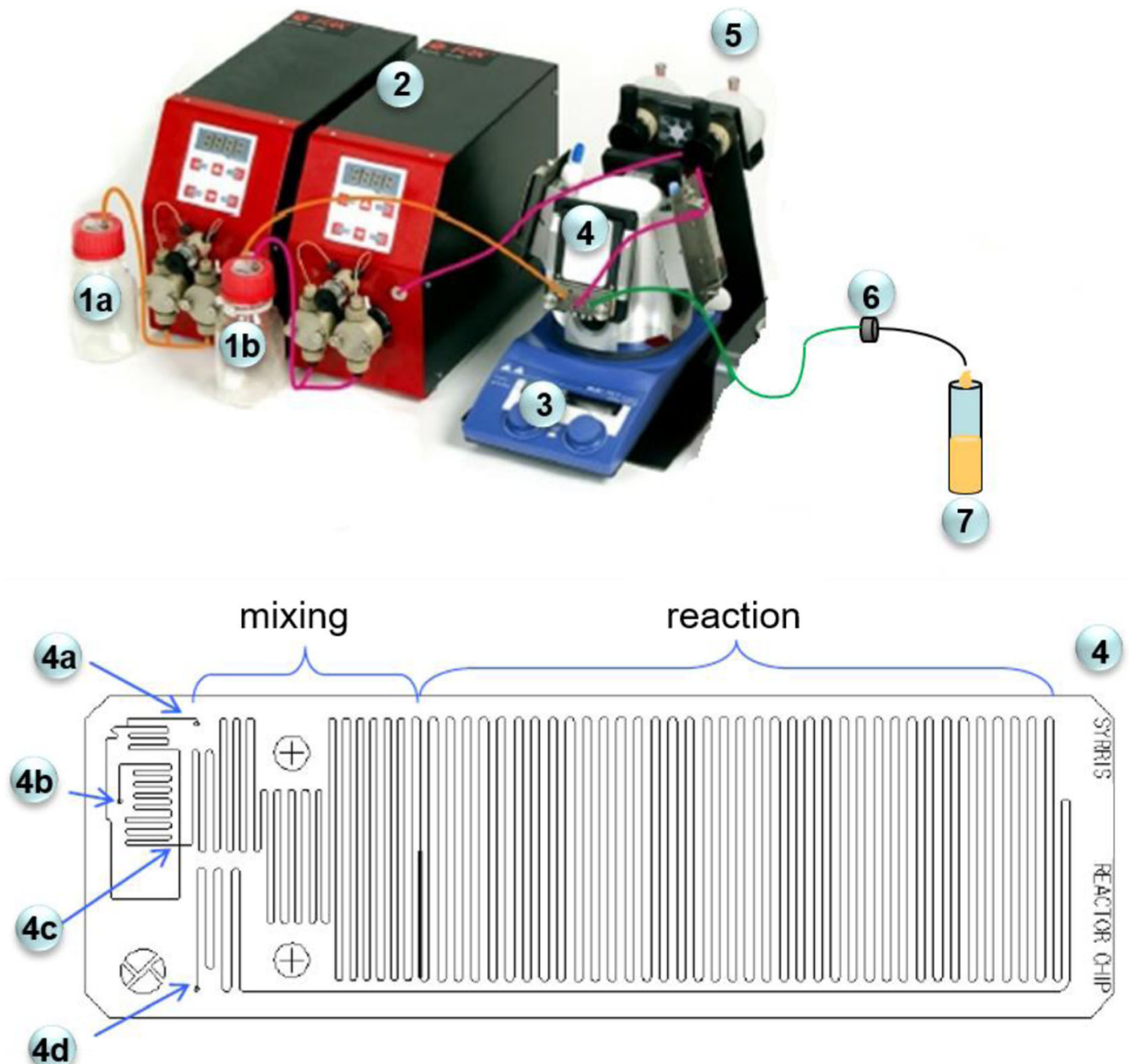

Fig. 1 The scheme of microreactor system used for continuous PdNP synthesis and their deposition on active carbon fibers. $1 \mathrm{a}-\mathrm{a}$ reservoir for the reducer, $1 \mathrm{~b}$ - water, 2 - a pump, 3-a thermostat,

of Pd(II) ions into orange, brown, and gray suggests formation of metal on zero oxidation state.

The obtained colloids were analyzed spectrophotometrically and the registered spectra are shown in Fig. 3. As it was expected, the highest level of turbidity was obtained for the highest amount of metal precursor. As a result of reaction between reagents with their smallest concentration (i.e., $0.05 \mathrm{mM} \mathrm{Pd(II)} \mathrm{and} 0.1 \mathrm{mM}$ ascorbic acid), a peak at about $250 \mathrm{~nm}$ was registered. Taking into account that reduction reaction between palladium(II) ions and ascorbic acid requires two donors, the observed peak can be associated with an unreacted reductant. For higher reductant concentration, the increase of absorbance level in the range of $280-500 \mathrm{~nm}$ was observed. In accordance with the
4 - a microchip, $4 \mathrm{a}$ - reductant input, $4 \mathrm{~b}$ - metal precursor input, $4 \mathrm{c}$ - double T-mixing junction, 4d-fluid output, 5-a reservoir for $\mathrm{Pd}(\mathrm{II})$ ions, 6 - filter with active carbon fibers, 7- sample

literature, the plasmon resonance can be observed for palladium particles bigger in diameter than $40 \mathrm{~nm}$ (Sugawa et al. 2015). However, in practice, we do not observe any spectrum with visible maximum, which can be explained by unreacted subtract and/or product spectrum overlap.

The presence of nanoparticles was confirmed by the use of DLS method, and the obtained values of the radius are gathered in Table 2 .

It was found that with an increasing amount of palladium(II) ions, the size of particles is decreasing. It can also be seen that polydispersity also decreases. In order to confirm the obtained results, colloidal palladium was examined with SEM microscopy (Fig. 4). 
Table 1 Experiment conditions for palladium nanoparticle synthesis in microreactor and PdNP deposition on ACF

\begin{tabular}{|c|c|c|c|}
\hline \multicolumn{2}{|c|}{ Reagents concentration } & \multirow[t]{2}{*}{ Temperature, $T\left({ }^{\circ} \mathrm{C}\right)$} & \multirow[t]{2}{*}{$\mathrm{pH}$} \\
\hline$C_{0, \mathrm{Pd}(\mathrm{II})}(\mathrm{mM})$ & $C_{0, \mathrm{H} 2 \mathrm{Asc}}(\mathrm{mM})$ & & \\
\hline \multicolumn{4}{|c|}{ An influence of initial concentration of metal precursor } \\
\hline 0.05 & 0.1 & 40 & 3.1 \\
\hline 0.10 & 0.2 & & \\
\hline 0.20 & 0.4 & & \\
\hline 0.30 & 0.6 & & \\
\hline 0.40 & 0.8 & & \\
\hline 0.50 & 1.0 & & \\
\hline \multicolumn{4}{|c|}{ An influence of initial concentration of reductant } \\
\hline \multirow[t]{5}{*}{0.2} & 0.1 & & \\
\hline & 0.2 & & \\
\hline & 0.4 & 40 & 3.5 \\
\hline & 0.6 & & \\
\hline & 0.8 & & \\
\hline
\end{tabular}

SEM analysis showed that the size of obtained palladium nanoparticles slightly decreases with increasing initial concentration of $\mathrm{Pd}(\mathrm{II})$ ions in the reacting solution. The size distribution also decreases. The obtained palladium nanoparticles are irregular in shape and usually form spherical clusters. Some aggregates were also formed.

The influence of initial concentration of reductant

As a result of mixing $0.2 \mathrm{mM}$ solution of the chloride palladium with different amounts of ascorbic acid in the flow microreactor, colloids with a "light brown" color

Table 2 The values of the radius $\left(\mathbf{R}_{\mathbf{n}}, \mathbf{R}_{\mathbf{i}}\right.$, calculated by the number (n) and the intensity (i), respectively) of palladium nanoparticles with standard deviation $(\sigma)$

\begin{tabular}{llll}
\hline $\mathrm{C}_{0, \mathrm{Pd}(\mathrm{IV})}(\mathrm{mM})$ & $\mathrm{C}_{0, \mathrm{AA}}(\mathrm{mM})$ & $\mathrm{R}_{\mathrm{n}} \pm \sigma(\mathrm{nm})$ & $\mathrm{R}_{\mathrm{i}} \pm \sigma(\mathrm{nm})$ \\
\hline 0.05 & 0.1 & $23.9 \pm 7.9$ & $57.3 \pm 25.9$ \\
0.1 & 0.2 & $23.5 \pm 7.7$ & $54.5 \pm 23.2$ \\
0.2 & 0.4 & $15.6 \pm 4.1$ & $29.0 \pm 11.2$ \\
0.3 & 0.6 & $12.3 \pm 3.4$ & $24.4 \pm 9.6$ \\
0.4 & 0.8 & $13.1 \pm 3.7$ & $25.0 \pm 9.3$ \\
\hline
\end{tabular}

Conditions: $\mathrm{C}_{0, \mathrm{Pd}(\mathrm{II})}=0.05-0.4 \mathrm{mM}, \mathrm{C}_{0, \mathrm{AA}}=0.1-0.8 \mathrm{mM}, T=$ $40{ }^{\circ} \mathrm{C}, I=0.0 \mathrm{M}, \mathrm{C}_{0}, \mathrm{Cl}^{-}=0.0 \mathrm{M}$

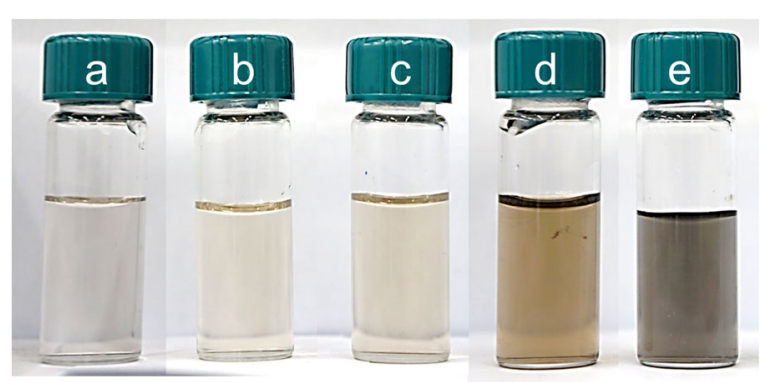

Fig. 2 Colloidal palladium obtained in microreactor as a result of reduction reaction $\mathrm{Pd}(\mathrm{II})$ ions with $\mathrm{L}$-ascorbic acid. Conditions: $\mathrm{C}_{0, \mathrm{Pd}(\mathrm{II})}=0.05-0.4 \mathrm{mM}, \mathrm{C}_{0, \mathrm{AA}}=0.1$ (a) $-0.8 \mathrm{mM}(\mathbf{f}), T=40^{\circ} \mathrm{C}$, $\mathrm{C}_{0, \mathrm{Cl}^{-}}=0.0 \mathrm{M}$

were obtained (Fig. 5a-e). The change in color indicates that a solid phase appears in the analyzed solutions.

It was confirmed when solutions containing palladium were analyzed spectrophotometrically. The obtained results are shown in Fig. 6. In all cases, an increase in the absorbance in the visible light was observed, indicating the appearance of the metallic phase. The presence of palladium nanoparticles was confirmed by dynamic light scattering experiment, and the obtained values of hydrodynamic radius are summarized in Table 3. For smaller amount of ascorbic acid, i.e., 0.1 and $0.2 \mathrm{mM}$, unreacted $\mathrm{Pd}(\mathrm{II})$ ions were identified, since on registered spectrum, two peaks are visible, which are characteristic of palladium complex $\left(\lambda_{\max , 1}=207 \mathrm{~nm}\right.$ and $\left.\lambda_{\max , 2}=236 \mathrm{~nm}\right)$. For higher amount of reductant, unreacted ascorbic acid was identified, i.e., the characteristic peak was observed at about $250 \mathrm{~nm}$.

Basing on the obtained hydrodynamic radius (Table 3), it is difficult to find the influence of the concentration of the reductant on the size of palladium nanoparticles. The radius values $\left(R_{n}\right)$ ranged from $20.5 \pm 6.0$ to $37.1 \pm 14.4 \mathrm{~nm}$. In addition, the synthesized palladium nanoparticles were analyzed using SEM, and the obtained results are shown in Fig. 7a-d. For the lowest initial concentration of Lascorbic acid, spherical particles (Fig. 7a) with a diameter of about $50 \mathrm{~nm}$ were obtained.

For higher concentrations of the reducer, i.e., 0.4 and $0.8 \mathrm{mM}$, palladium nanoparticles of different shapes like sphere, tetrahedron, and cube are obtained (Fig. 7c, d). These shapes suggest that the nanoparticle growth mechanism and their appearance can be controlled by a reducer, which confirms our previous findings (LutyBłocho et al. 2018). 
Fig. 3 UV-Vis spectra of metallic phase obtained as a result of reduction reaction between $\mathrm{Pd}(\mathrm{II})$ ions and ascorbic acid conducted in microreactor at $\mathrm{FR}=6.0 \mathrm{ml} /$ min. Conditions: $\mathrm{C}_{0 \text {, } \mathrm{Pd}(\mathrm{II})}=0.05$ $0.4 \mathrm{mM}, \mathrm{C}_{0, \mathrm{AA}}=0.1-0.8 \mathrm{mM}$, $T=40{ }^{\circ} \mathrm{C}, I=0.0 \mathrm{M}, \mathrm{C}_{0, \mathrm{Cl}^{-}}=$ $0.0 \mathrm{M}$

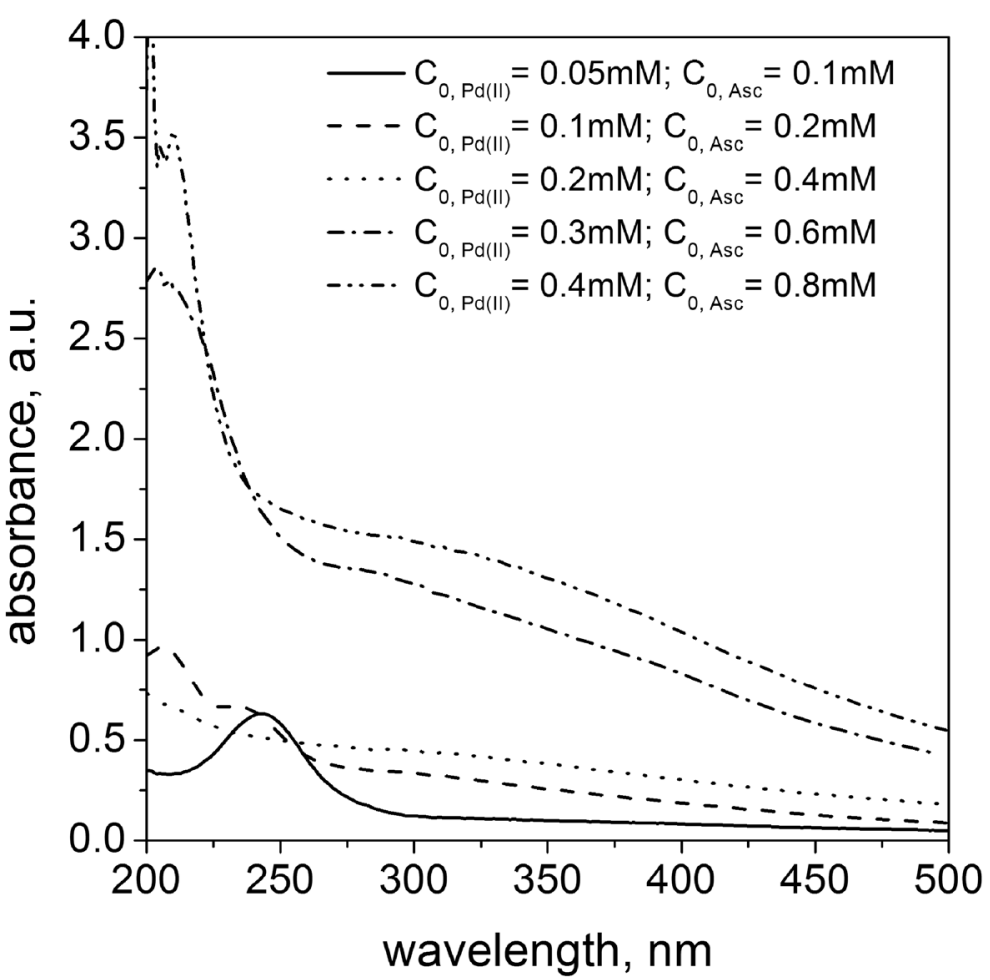

PdNP deposition on ACF

\section{Deposition in microflow}

Having determined the influence of Pd(II) and reductant concentration on the size and shape, we used this knowledge to produce hybrid material. It can be done by mixing metal precursor with reductant in volume ratio 1:1 in a microreactor chip (part 4 in Fig. 1). In the first stage, reagents are introduced to the separate microchannels in a microchip. The stream (4a; Fig. 1) consisting of reductant is split into two parts, which are directed to the $T$-shaped micromixer (4c; Fig. 1). In this place, two streams with reductant are introduced to the stream with metal ions and the mixing process starts. After that, the reduction reaction between $\mathrm{Pd}(\mathrm{II})$ ions and L-ascorbic acid takes place followed by steps like nucleation and autocatalytic grow of palladium nanoparticles. As a result of this process, at the end of the reactor, palladium nanoparticles are formed.

After synthesis, the palladium particles are directed to the microcapillary with the filter in which carbon carrier was closed (Fig. 1). The obtained solutions with PdNPs were analyzed twice, first before and then after passing through the filter with carbon fibers. The results of these experiments (Fig. 8) show that the solutions after passing through the filter "discolored." This demonstrates that palladium nanoparticles are adsorbed on the surface of the active carbon fibers.

The obtained colloids were analyzed sepctrophotometrically and the obtained results are shown in Fig. 8a-e. For each colloid, characteristic spectra in the visible range were registered (Fig. 9). It was observed that spectral intensity related to the solution after passing it through the filter with active carbon fibers decreases. The obtained results prove that palladium nanoparticles have been adsorbed on the ACF surface.

However, they also indicate that active carbon fibers may adsorb ascorbic acid (see Fig. 9a), which was confirmed by a separate test (see, Supplementary materials, Fig. S1). Moreover, for higher amount of $\mathrm{Pd}(\mathrm{II})$ ions in the solution, rebuilding of the spectrum band was registered with maximum at 207 and $236 \mathrm{~nm}$ after passing to the filter. The registered spectrum indicates the presence of $\mathrm{Pd}(\mathrm{II})$ ions in the 


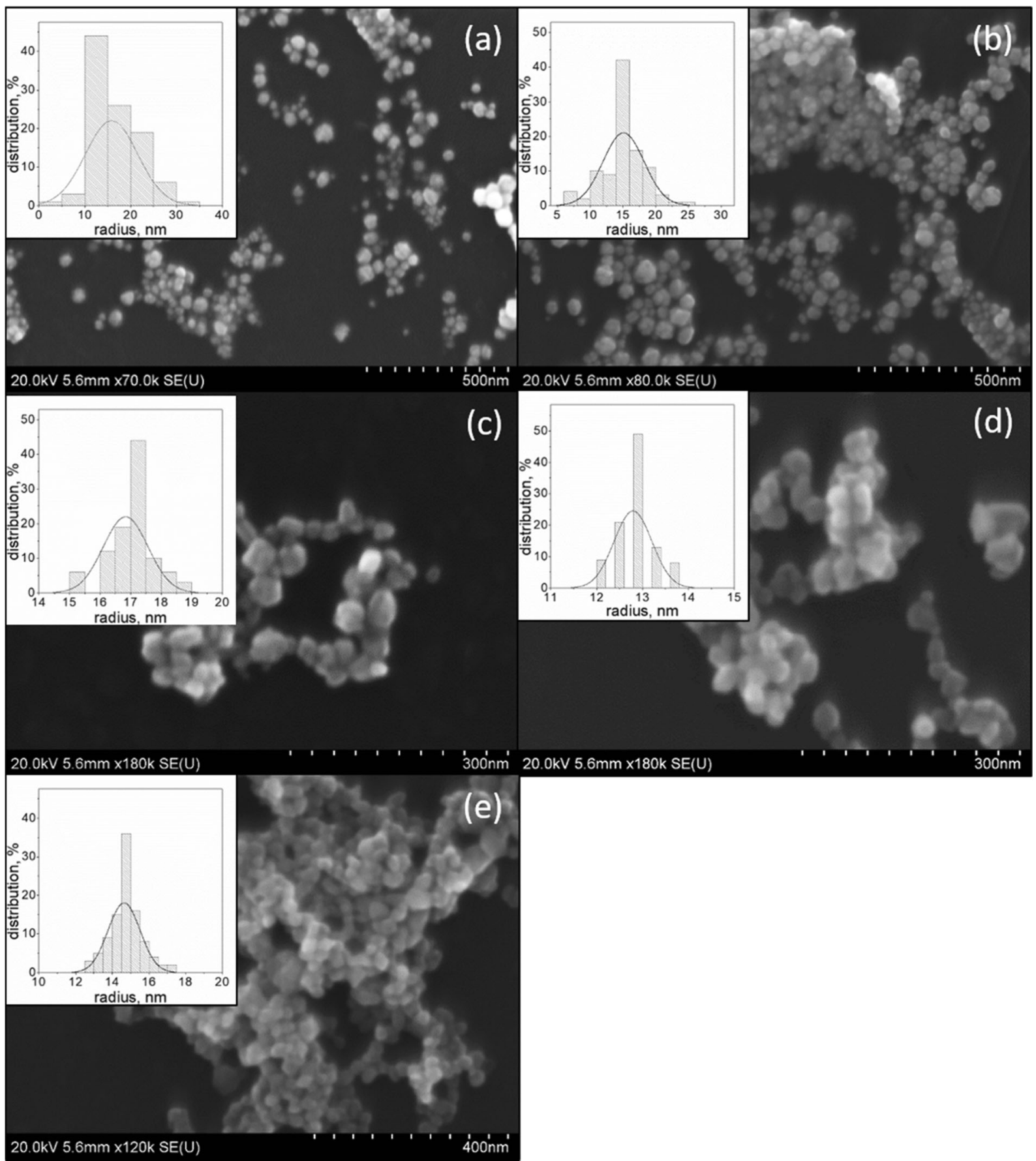

Fig. 4 PdNPs obtained in results of reduction reaction Pd(II) $0.1 \mathrm{mM}, \mathrm{C}_{0, \mathrm{AA}}=0.2 \mathrm{mM}$. $\mathrm{c}_{0, \mathrm{Pd}(\mathrm{II})}=0.2 \mathrm{mM}, \mathrm{C}_{0, \mathrm{AA}}=0.4 \mathrm{mM}$. chloride complex ions with ascorbic acid and their size distribution. Conditions: $\mathrm{FR}=6.0 \mathrm{~mL} / \mathrm{min}, T=40^{\circ} \mathrm{C}, I=0.0 \mathrm{M}, \mathrm{C}_{0}, \mathrm{Cl}^{-}=$ d $\mathrm{C}_{0, \mathrm{Pd}(\mathrm{II})}=0.3 \mathrm{mM}, \mathrm{C}_{0, \mathrm{AA}}=0.6 \mathrm{mM}$. e $\mathrm{C}_{0, \mathrm{Pd}(\mathrm{II})}=0.4 \mathrm{mM}, \mathrm{C}_{0}$, 0.0 M. a $\mathrm{C}_{0, \mathrm{Pd}(\mathrm{II})}=0.05 \mathrm{mM}, \mathrm{C}_{0, \mathrm{AA}}=0.1 \mathrm{mM}$. b $\mathrm{C}_{0, \mathrm{Pd}(\mathrm{II})}=$ $\mathrm{AA}=0.8 \mathrm{mM}$ 


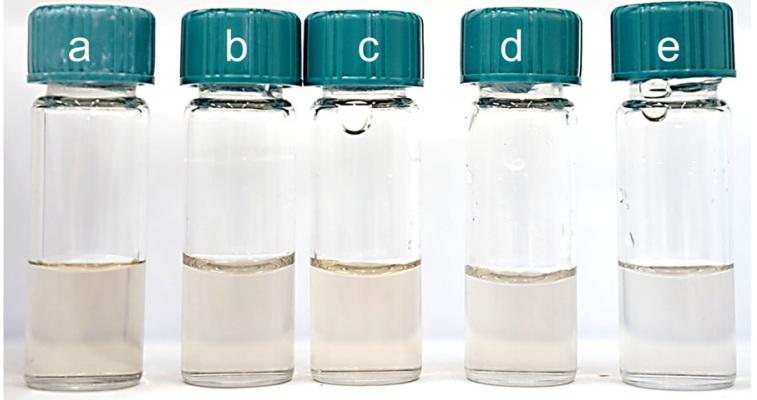

Fig. 5 Colloidal palladium obtained in microreactor as a result of reduction reaction of $\mathrm{Pd}(\mathrm{II})$ ions with $\mathrm{L}$-ascorbic acid. Conditions: $\mathrm{C}_{0, \mathrm{Pd}(\mathrm{II})}=0.2 \mathrm{mM}, \mathrm{C}_{0, \mathrm{AA}}=0.1$ (a) $-0.8 \mathrm{mM}$ (f), $T=40^{\circ} \mathrm{C}, I=$ $0.0 \mathrm{M}, \mathrm{C}_{0, \mathrm{Cl}^{-}}=0.0 \mathrm{M}$

waste solution, and suggests that following reactions take place:

$P d+\frac{1}{2} O_{2} \leftrightarrow P d O$

$\mathrm{PdO}+\mathrm{HCl} \leftrightarrow \mathrm{PdCl}_{2}+\mathrm{H}_{2} \mathrm{O}$
Table 3 The values of radius $\left(\mathbf{R}_{\mathbf{n}}, \mathbf{R}_{\mathbf{i}}\right.$, calculated by the number (n) and the intensity (i), respectively) of palladium nanoparticles with standard deviation $(\sigma)$

\begin{tabular}{lllc}
$\mathrm{C}_{0, \mathrm{AA}}(\mathrm{mM})$ & $\mathrm{R}_{\mathrm{n}} \pm \sigma(\mathrm{nm})$ & $\mathrm{R}_{\mathrm{i}} \pm \sigma(\mathrm{nm})$ & Color of the solution \\
\hline 0.1 & $24.6 \pm 6.4$ & $41.9 \pm 14.2$ & Pale brown \\
0.2 & $31.0 \pm 8.6$ & $50.2 \pm 15.8$ & \\
0.4 & $20.5 \pm 6.0$ & $45.9 \pm 20.5$ & \\
0.6 & $25.5 \pm 7.6$ & $51.2 \pm 20.3$ & \\
0.8 & $37.1 \pm 14.4$ & $70.1 \pm 27.2$ & \\
\hline
\end{tabular}

Conditions: $\mathrm{C}_{0, \mathrm{Pd}(\mathrm{II})}=0.2 \mathrm{mM}, \mathrm{C}_{0, \mathrm{AA}}=0.1-0.8 \mathrm{mM}, T=40^{\circ} \mathrm{C}$, $I=0.0 \mathrm{M}, \mathrm{C}_{0, \mathrm{Cl}^{-}}=0.0 \mathrm{M}$

which yields overall reaction

$\mathrm{Pd}+\frac{1}{2} \mathrm{O}_{2}+2 \mathrm{HCl} \leftrightarrow \mathrm{PdCl}_{2}+\mathrm{H}_{2} \mathrm{O}$

For this reaction $\Delta \mathrm{G}_{\mathrm{T}}^{\circ}=-269 \mathrm{~kJ}$ and the obtained negative value of Gibbs free energy means that this process (i.e., reaction between metallic palladium and oxygen dissolved in the solution) is spontaneous.

Samples of colloidal palladium used in experiments were also analyzed using DLS method, and the results are summarized in Table 4.
Fig. 6 UV-Vis spectra of metallic phase obtained as a result of reduction reaction between $\mathrm{Pd}(\mathrm{II})$ ions with ascorbic acid conducted in microreactor at $\mathrm{FR}=6.0 \mathrm{~mL}$ min. Conditions: $\mathrm{C}_{0}, \mathrm{Pd}(\mathrm{II})=$ $0.2 \mathrm{mM}, \mathrm{C}_{0, \mathrm{AA}}=0.1-0.8 \mathrm{mM}$, $T=40{ }^{\circ} \mathrm{C}, I=0.0 \mathrm{M}, \mathrm{C}_{0}, \mathrm{Cl}^{-}=$ $0.0 \mathrm{M}$

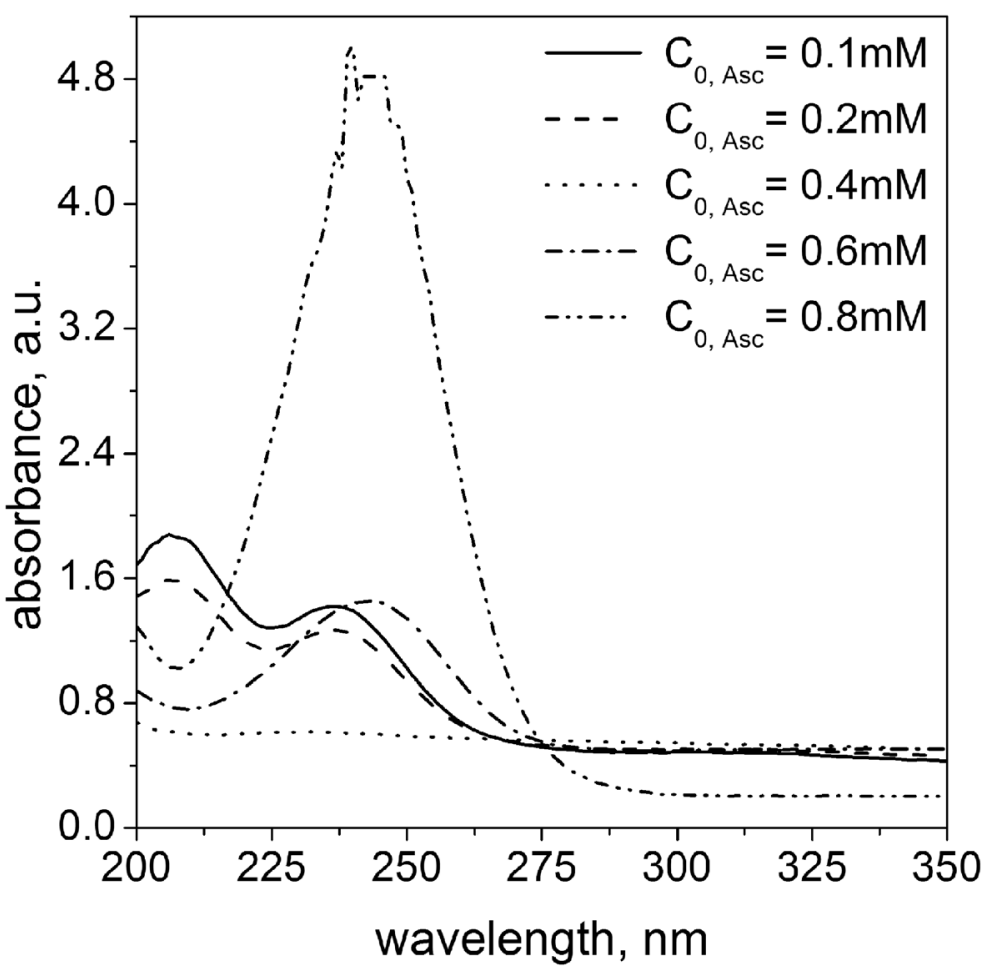




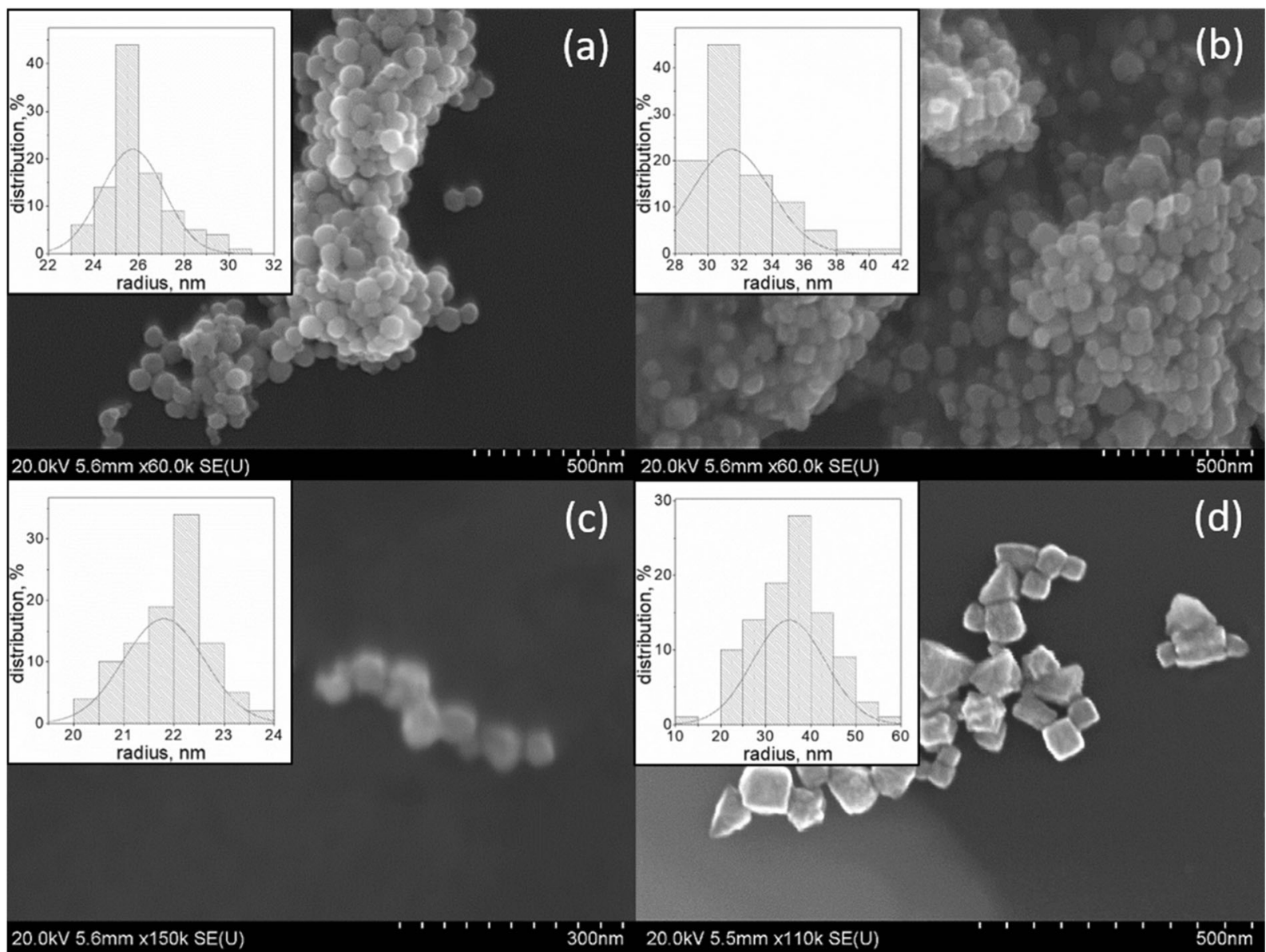

Fig. 7 PdNPs obtained as a result of reduction reaction Pd(II) chloride complex ions with ascorbic acid and their size distribution. Conditions: $T=40^{\circ} \mathrm{C}, I=0.0 \mathrm{M}, \mathrm{C}_{0, \mathrm{Cl}^{-}}=0.0 \mathrm{M}, \mathrm{C}_{0, \mathrm{Pd}(\mathrm{II})}=$
$0.2 \mathrm{mM}$. a $\mathrm{C}_{0, \mathrm{AA}}=0.1 \mathrm{mM}$. b $\mathrm{C}_{0, \mathrm{AA}}=0.2 \mathrm{mM}$. $\mathbf{c} \mathrm{C}_{0, \mathrm{AA}}=$ $0.4 \mathrm{mM} . \mathrm{d} \mathrm{C}_{0, \mathrm{AA}}=0.8 \mathrm{mM}$

performed to verify the efficiency of the particle deposition process on activated carbon fiber surface. The results are presented in Fig. 10a-h.

It was found that the palladium nanoparticle deposition on activated carbon fibers (Fig. 10a) is not effective (Fig. 10b, c) for the lowest palladium(II) precursor concentrations, i.e., 0.05 and $0.1 \mathrm{mM}$. Too small amount of introduced ions makes the amount of

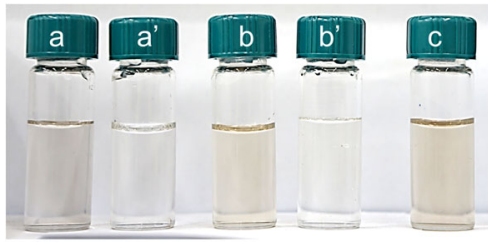

Fig. 8 Colors obtained solutions containing palladium nanoparticles resulting from the reduction of the chloride complex of $\mathrm{Pd}$ (II) with L-ascorbic. Conditions: $\mathrm{C}_{0, \mathrm{Pd}(\mathrm{II})}=0.05-0.4 \mathrm{mM}, \mathrm{C}_{0, \mathrm{AA}}=0.1$

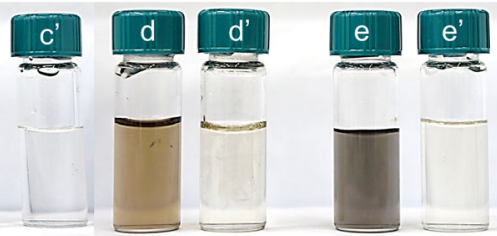

(a) $-0.8 \mathrm{mM}\left(\mathbf{e}^{\prime}\right), T=40^{\circ} \mathrm{C}, I=0.0 \mathrm{M}, \mathrm{C}_{0, \mathrm{Cl}^{-}}=0.0 \mathrm{M}$. a-e denote sample before solution passing through filter with ACF, and $\mathbf{a}^{\prime}-\mathbf{e}^{\prime}$ after solution passing through filter 

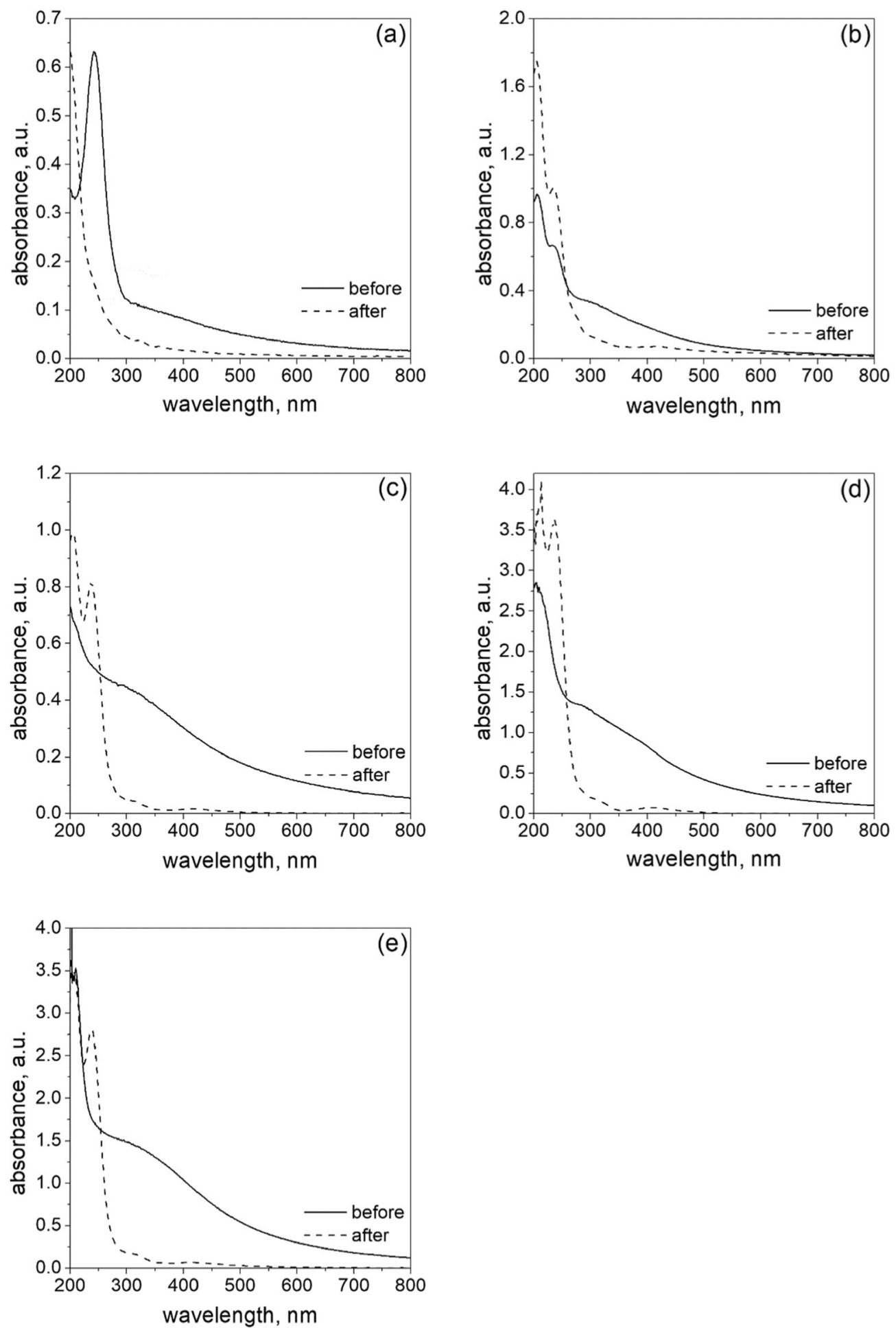

Fig. 9 UV-Vis spectrum colloidal phase of palladium obtained as a result of reduction reaction of $\mathrm{Pd}(\mathrm{II})$ ions with $\mathrm{L}$-ascorbic acid. Conditions: $\mathrm{FR}=6.0 \mathrm{~mL} / \mathrm{min}, T=40^{\circ} \mathrm{C}, I=0.0 \mathrm{M}, \mathrm{C}_{0}, \mathrm{Cl}^{-}=$ $0.0 \mathrm{M}, \mathrm{C}_{0, \operatorname{Pd}(\mathrm{II})}=0.05 \mathrm{mM}, \mathrm{C}_{0, \mathrm{AA}}=0.1 \mathrm{mM}(\mathbf{a}) . \mathrm{C}_{0, \operatorname{Pd}(\mathrm{II})}=$

$0.1 \mathrm{mM}, \mathrm{C}_{0, \mathrm{AA}}=0.2 \mathrm{mM}$ (b). $\mathrm{C}_{0, \mathrm{Pd}(\mathrm{II})}=0.2 \mathrm{mM}, \mathrm{C}_{0, \mathrm{AA}}=$ $0.4 \mathrm{mM}(\mathbf{c}) \cdot \mathrm{C}_{0, \mathrm{Pd}(\mathrm{II})}=0.3 \mathrm{mM}, \mathrm{C}_{0, \mathrm{AA}}=0.6 \mathrm{mM}(\mathbf{d}) \cdot \mathrm{C}_{0, \operatorname{Pd}(\mathrm{II})}=$ $0.4 \mathrm{mM}, \mathrm{C}_{0, \mathrm{AA}}=0.8 \mathrm{mM}(\mathbf{e})$ 
Table 4 The values of radius $\left(\mathbf{R}_{\mathbf{n}}, \mathbf{R}_{\mathbf{i}}\right.$, calculated by number (n) and intensity (i), respectively) of palladium nanoparticles with standard deviation $(\sigma)$

\begin{tabular}{|c|c|c|c|c|c|c|}
\hline $\mathrm{C}_{0, \operatorname{Pd}(\mathrm{IV})}(\mathrm{mM})$ & $\mathrm{C}_{0, \mathrm{AA}}(\mathrm{mM})$ & Before $R_{n} \pm \sigma(\mathrm{nm})$ & After $R_{n} \pm \sigma(\mathrm{nm})$ & Before $R_{i} \pm \sigma(\mathrm{nm})$ & After $R_{i} \pm \sigma(\mathrm{nm})$ & Color \\
\hline 0.05 & 0.1 & $23.9 \pm 7.9$ & $29.0 \pm 8.0$ & $57.3 \pm 25.9$ & $49.0 \pm 16.3$ & \multirow[t]{5}{*}{ Brown } \\
\hline 0.1 & 0.2 & $23.5 \pm 7.7$ & $18.2 \pm 4.8$ & $54.5 \pm 23.2$ & $31.4 \pm 10.4$ & \\
\hline 0.2 & 0.4 & $15.6 \pm 4.1$ & $122 \pm 22$ & $29.0 \pm 11.2$ & $124 \pm 18$ & \\
\hline 0.3 & 0.6 & $12.3 \pm 3.4$ & $20.5 \pm 5.9$ & $24.5 \pm 9.6$ & $42.1 \pm 16.6$ & \\
\hline 0.4 & 0.8 & $13.1 \pm 3.7$ & $16.1 \pm 5.0$ & $25.0 \pm 9.3$ & $44.2 \pm 22.8$ & \\
\hline
\end{tabular}

Conditions: $\mathrm{C}_{0, \mathrm{Pd}(\mathrm{II})}=0.05-0.4 \mathrm{mM}, \mathrm{C}_{0, \mathrm{AA}}=0.1-0.8 \mathrm{mM}, T=40^{\circ} \mathrm{C}, I=0.0 \mathrm{M}, \mathrm{C}_{0, \mathrm{Cl}^{-}}=0.0 \mathrm{M}$

synthesized nanoparticles small, and therefore, the degree of fibers coverage is negligible. For higher concentrations of Pd(II) ions, i.e., above $0.2 \mathrm{mM}$, the degree of fiber surface coverage increased significantly (Fig. 10d-h). The highest degree of carbon fiber coverage was obtained for the highest values of metal ion concentrations (Fig. 10e-h). It has also been observed that palladium nanoparticles (Fig. 10e, g) are separated from the fiber at some locations. For the highest concentration of the initial palladium precursor, it was noted that the particles "stick together" to form a nanometric layer (Fig. 10h).

\section{Deposition in a batch reactor}

In order to prove the advantage of a microreactor, the process of palladium nanoparticle deposition on ACF was also carried out in a batch reactor. This process for PdNP synthesis was conducted for selected conditions, i.e., $0.3 \mathrm{mM}$ of $\mathrm{Pd}(\mathrm{II})$ ions and $0.6 \mathrm{mM}$ of ascorbic acid at $40{ }^{\circ} \mathrm{C}$, which were found to be optimal for the synthesis in a microreactor. Solutions of metal precursor and reductant were heated up to $40{ }^{\circ} \mathrm{C}$, and then, they were simultaneously mixed in volumetric ratio $1: 1$. After few seconds, the yellow color of the solution (coming from $\mathrm{Pd}(\mathrm{II})$ ions) turned into brown. This color change and registered spectrum (Fig. 11a) confirm that nanoparticles are formed. This colloidal palladium was added to the active carbon fibers $(0.01 \mathrm{~g})$ and mixed. The process of impregnation was carried out for $1 \mathrm{~h}$. Next, the active carbon fibers were separated from the colloidal palladium and dried at $50{ }^{\circ} \mathrm{C}$ for $4 \mathrm{~h}$. The colloidal palladium before and after impregnation process was examined using spectrophotometric and DLS methods. In addition, active carbon fibers after impregnation stage were analyzed using SEM. The result of this analysis is shown in Fig. 11b.
As it can be seen (Fig. 11a), the spectrum for colloidal palladium changed after impregnation step. It suggests that either some palladium particles can be adsorbed on ACF or some aggregates are formed. Similarly to the synthesis carried out in a microreactor, the reappearance of the spectrum band was registered after impregnation stage with maximum at 207 and $236 \mathrm{~nm}$. It was also observed that during impregnation of ACF, the solution changed color to darker one (Fig. 11a), and this result is opposite to the effect observed in a microreactor (Fig. 8d, $\mathrm{d}^{\prime}$ ). It suggests that the PdNP deposition on ACF carried out in a batch reactor is ineffective even after much longer time than it took in a microreactor. Hydrodynamic radius indicates that the size of particles obtained in a batch route before impregnation equals $8.4 \pm 1.8 \mathrm{~nm}(95.5 \%)$ and $22.8 \pm 9.8(4.5 \%)$ (values calculated by number). After impregnation step, the size of obtained particles is equal to $21.1 \pm 6.6(100 \%)$. It suggests that during $1 \mathrm{~h}$, the size of particles in the solution enlarged. Microscopic analysis was performed to verify the efficiency of the particle deposition process on activated carbon fiber surface. The result is presented in Fig. 11b. It can be seen that the amount of deposited particles on the ACF is much lower than in case of the process conducted in a microreactor (Fig. 10f).

\section{Conclusions}

As a result of $\mathrm{Pd}(\mathrm{II})$ reduction with $\mathrm{L}$-ascorbic acid and nucleation and growth of nanoparticles in a flow microreactor, it was possible to obtain palladium nanoparticles of different sizes, size distribution, and shapes in one cycle. On the one hand, no significant effect of the reducer concentration on the size of the resulting particles was observed. On the other hand, it has been observed that as the concentration of L-ascorbic acid 


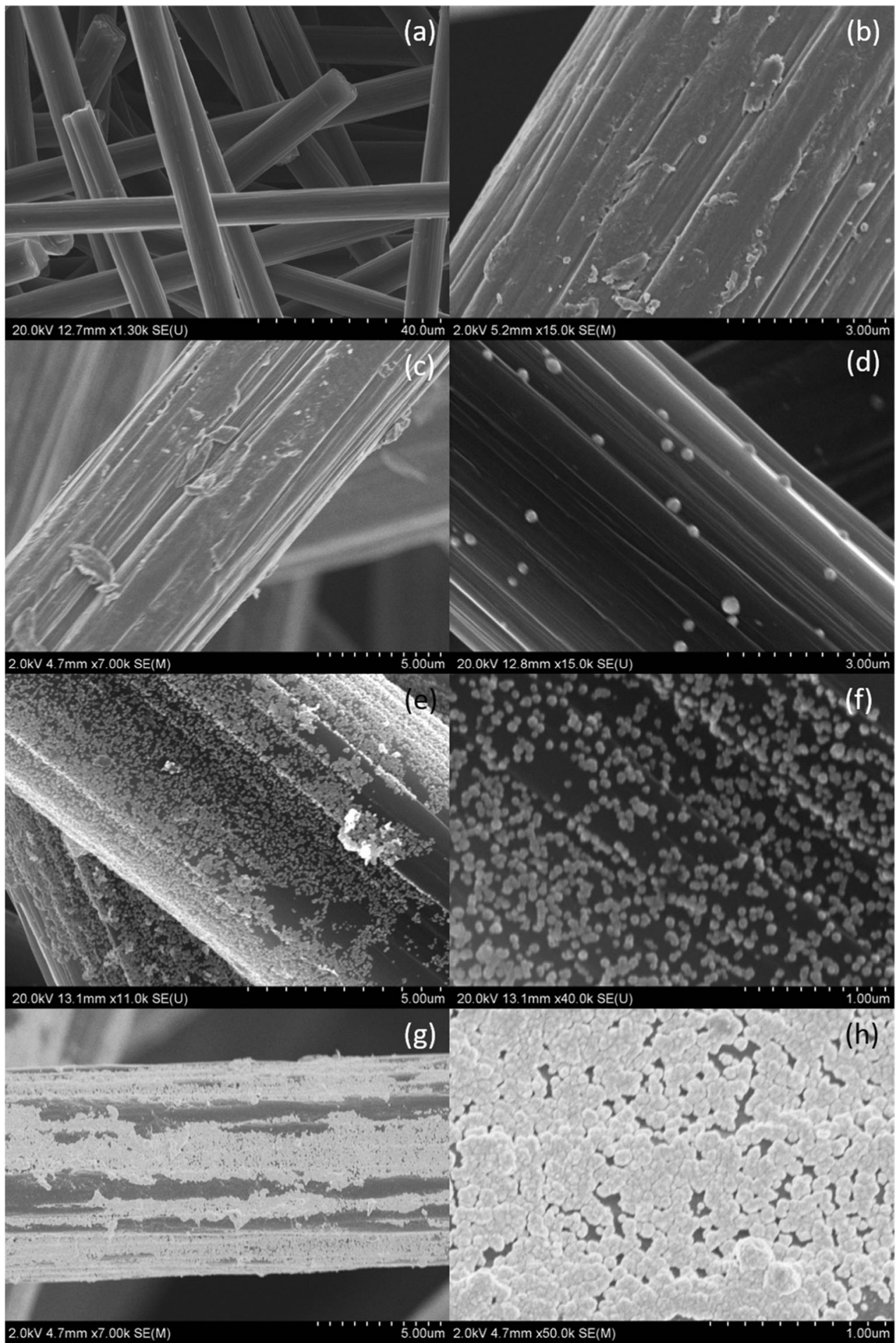

Fig. $10 \mathrm{Pd} / \mathrm{ACF}$ catalyst obtained as a result of nanoparticle synthesis in microreactor and their deposition on active carbon fibers. Conditions: $\mathrm{FR}=6.0 \mathrm{~mL} / \mathrm{min}, T=40{ }^{\circ} \mathrm{C}, I=0.0 \mathrm{M}, \mathrm{C}_{0}$, $\mathrm{Cl}^{-}=0.0 \mathrm{M}$. a Active carbon fibers. b $\mathrm{C}_{0, \mathrm{Pd}(\mathrm{II})}=0.05 \mathrm{mM}, \mathrm{C}_{0}$,
$\mathrm{AA}=0.1 \mathrm{mM} . \mathbf{c ~ C}_{0, \mathrm{Pd}(\mathrm{II})}=0.1 \mathrm{mM}, \mathrm{C}_{0, \mathrm{AA}}=0.2 \mathrm{mM} \cdot \mathbf{d ~ C}_{0, \operatorname{Pd}(\mathrm{II})}=$ $0.2 \mathrm{mM}, \mathrm{C}_{0, \mathrm{AA}}=0.4 \mathrm{mM}$. e, $\mathbf{f ~ C}_{0, \mathrm{Pd}(\mathrm{II})}=0.3 \mathrm{mM}, \mathrm{C}_{0, \mathrm{AA}}=$ $0.6 \mathrm{mM} . \mathbf{g}, \mathbf{h} \mathrm{C}_{0, \mathrm{Pd}(\mathrm{II})}=0.4 \mathrm{mM}, \mathrm{C}_{0, \mathrm{AA}}=0.8 \mathrm{mM}$ 


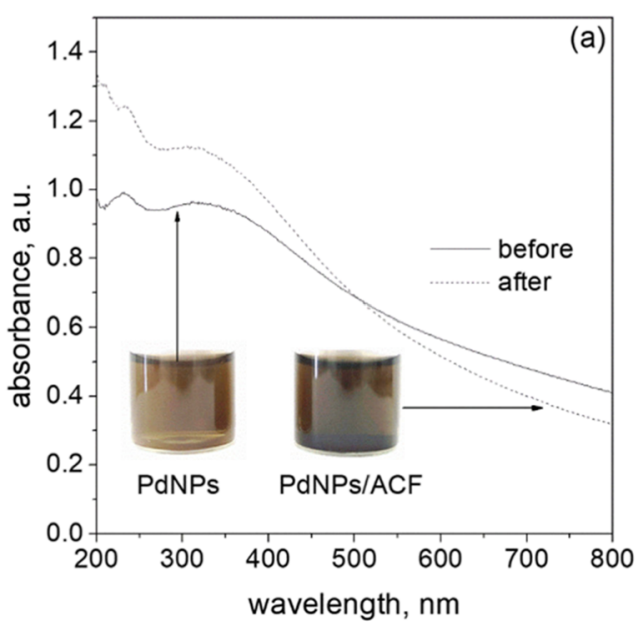

Fig. 11 UV-Vis spectrum of the colloidal phase of palladium obtained as a result of reduction reaction of $\mathrm{Pd}(\mathrm{II})$ ions with Lascorbic acid in a batch reactor. Conditions: $T=40^{\circ} \mathrm{C}, I=0.0 \mathrm{M}$, $\mathrm{C}_{0, \mathrm{Pd}(\mathrm{II})}=0.3 \mathrm{mM}, \mathrm{C}_{0, \mathrm{AA}}=0.6 \mathrm{mM}(\mathbf{a}) . \mathrm{Pd} / \mathrm{ACF}$ obtained as a

increases, the shape of the resulting palladium nanoparticles is more diverse.

It was found that at constant temperature of $40{ }^{\circ} \mathrm{C}$ and the total flow rate of the reactants of $6.0 \mathrm{ml} / \mathrm{min}$, palladium nanoparticles were obtained, which are similar in irregular shape and size in the range from 10 to $50 \mathrm{~nm}$. Microscopic observations revealed the presence of aggregates (Fig. 10g, h) for higher values of concentration of $\mathrm{Pd}(\mathrm{II})$ ions.

The use of the flow allowed for the simultaneous synthesis of particles and their immediate deposition on carbon fibers in one step. Depending on the initial reactant concentrations, different levels of carbon fiber surface coverage were obtained. The best coverage and particles distribution of Pd deposited on ACF were obtained for $0.3 \mathrm{mM}$ solution of metal precursor and $0.6 \mathrm{mM}$ solution of reductant (Fig. 10e, f). The radius of the deposited palladium nanoparticles ranged from 25 to $30 \mathrm{~nm}$. The experiment performed in the batch reactor carried out under optimal conditions speaks in favor of the process conducted in the microreactor. We showed that under optimal conditions, it is hardly possible to deposit PdNPs on ACF in the batch (Fig. 11b).

In general, application of microreactors has an advantage over batch reactor. Small size and high surface to volume ratio of the space for the reaction enable precise temperature control and high efficiency of heterogeneous mass transfer. Moreover, the possibility of combining reactors in parallel may enhance total production capacity

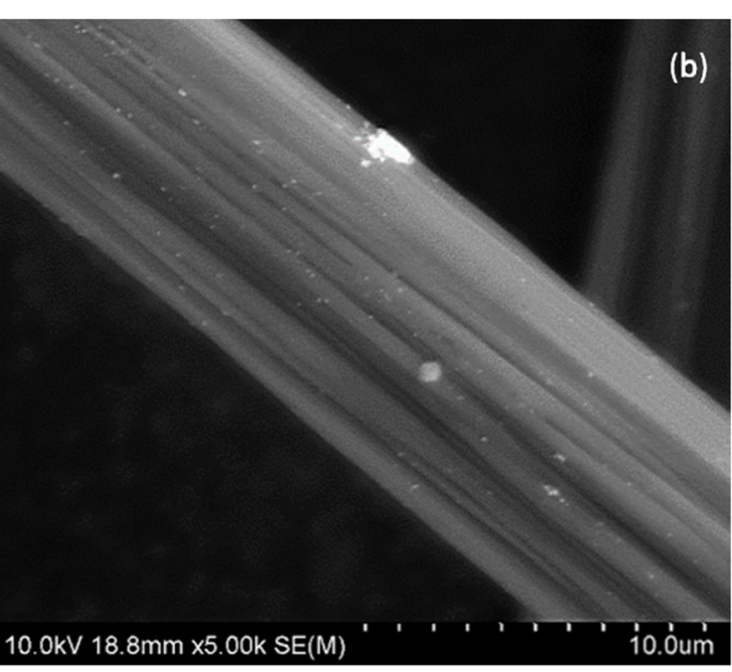

result of nanoparticles synthesis in a batch reactor and their deposition on active carbon fibers. Conditions: $\mathrm{T}=40^{\circ} \mathrm{C}, \mathrm{I}=0.0 \mathrm{M}, \mathrm{C}_{0}$, $\mathrm{Cl}^{-}=0.0 \mathrm{M}, \mathrm{C}_{0, \mathrm{Pd}(\mathrm{II})}=0.3 \mathrm{mM}, \mathrm{C}_{0, \mathrm{AA}}=0.6 \mathrm{mM}(\mathbf{b})$

over time. This technique can contribute to green sustainable chemical synthesis by decreasing energy consumption and reagents and by production of a small amount of waste. An additional advantage is the intensification of the process. The change in the construction of the microreactor may income the flow rates and to shorten residence time significant (Zhang et al. 2018).

Funding information This work was supported by the European Grant No. POIG.01.01.02-00-015/09-00.

\section{Compliance with ethical standards}

Conflict of interest The authors declare that they have no conflict of interest.

Open Access This article is distributed under the terms of the Creative Commons Attribution 4.0 International License (http:// creativecommons.org/licenses/by/4.0/), which permits unrestricted use, distribution, and reproduction in any medium, provided you give appropriate credit to the original author(s) and the source, provide a link to the Creative Commons license, and indicate if changes were made.

\section{References}

Brandão L, Rodrigues J, Madeira LM, Mendes A (2010) Methanol crossover reduction by Nafion modification with palladium composite nanoparticles: application to direct methanol fuel 
cells. Int J Hydrog Energy 35:11561-11567. https://doi. org/10.1016/j.jijydene.2010.04.096

Chen X, Li G, Zhang G, Hou K, Pan H, Du M (2016) Selfassembly of palladium nanoparticles on functional $\mathrm{TiO}_{2}$ nanotubes for a nonenzymatic glucose sensor. Mater Sci Eng C 62:323-328. https://doi.org/10.1016/j. msec.2016.01.068

Choi B, Ahn JH, Lee J, Yoon J, Lee J, Jeon M, Kim DM, Kim DH, Park I, Choi SJ (2015) A bottom-gate silicon nanowire fieldeffect transistor with functionalized palladium nanoparticles for hydrogen gas sensors. Solid State Electron 114:76-79. https://doi.org/10.1016/j.sse.2015.07.012

Cincotto FH, Golinelli DLC, Machado SAS, Moraes FC (2017) Electrochemical sensor based on reduced graphene oxide modified with palladium nanoparticles for determination of desipramine in urine samples. Sensors Actuators B Chem 239:488-493. https://doi.org/10.1016/j.snb.2016.08.063

Das RS, Singh B, Mandal A, Banerjee R, Mukhopadhyay S (2015) Kinetics of palladium nano-particles catalyzed reduction of methylene green by hydrazine: role of induction period in determining mechanistic pathway. Inorg Chim Acta 428:185-192. https://doi.org/10.1016/j.ica.2015.02.001

Dündar-Tekkaya E, Yürüm Y (2016) Synthesis of palladium incorporated MCM-41 via microwave irradiation and investigation of its hydrogen storage properties. Int J Hydrog Energy 41:9828-9833. https://doi.org/10.1016/j. ijhydene.2016.03.047

Ehrfeld W, Hessel V, Löwe H (2000) Microreactors : new technology for modern chemistry. Wiley-VCH Verlag, Weinheim

Fang J, Levchenko I, Lu X, Mariotti D, Ostrikov K (2015) Hierarchical bi-dimensional alumina/palladium nanowire nano-architectures for hydrogen detection, storage and controlled release. Int J Hydrog Energy 40:6165-6172. https://doi.org/10.1016/j.ijhydene.2015.02.134

Faye O, Szpunar JA, Szpunar B, Beye AC (2017) Hydrogen adsorption and storage on palladium - functionalized graphene with NH-dopant: a first principles calculation. Appl Surf Sci 392:362-374. https://doi.org/10.1016/j. apsusc.2016.09.032

Gómez-Martínez M, Buxaderas E, Pastor IM, Alonso DA (2015) Palladium nanoparticles supported on graphene and reduced graphene oxide as efficient recyclable catalyst for the Suzuki-Miyaura reaction of potassium aryltrifluoroborates. J Mol Catal A Chem 404-405:1-7. https://doi.org/10.1016/j. molcata.2015.03.022

Gupta D, Dutta D, Kumar M, Barman PB, Sarkar CK, Basu S, Hazra SK (2014) A low temperature hydrogen sensor based on palladium nanoparticles. Sensors Actuators B Chem 196: 215-222. https://doi.org/10.1016/j.snb.2014.01.106

Lemo J, Heuzé K, Astruc D (2006) Synthesis and catalytic activity of DAB-dendrimer encapsulated Pd nanoparticles for the Suzuki coupling reaction. Inorg Chim Acta 359:4909-4911. https://doi.org/10.1016/j.ica.2005.12.070

Li Y, Dai Y, Yang Z, Li T (2014) Controllable synthesis of palladium nanoparticles and their catalytic abilities in heck and Suzuki reactions. Inorg Chim Acta 414:59-62. https://doi.org/10.1016/j.ica.2014.01.041

Luty-Błocho M, Wojnicki M, Pacławski K, Fitzner K (2013) The synthesis of platinum nanoparticles and their deposition on the active carbon fibers in one microreactor cycle. Chem Eng J 226:46-51. https://doi.org/10.1016/j.cej.2013.04.008
Luty-Błocho M, Wojnicki M, Grzonka J, Kurzydłowski KJ (2014) The synthesis of stable platinum nanoparticles in the microreactor. Arch Metall Mater 59:509-512. https://doi. org/10.2478/amm-2014-0084

Luty-Błocho M, Wojnicki M, Grzonka J, Kurzydłowski K, Fitzner K (2018) Linking the gold nanoparticles formation kinetics with their morphology. In J Chem Kinet 50:204-214. https://doi.org/10.1002/kin.21152

Ma L, Zhang J-M, Xu K-W, Ji V (2015) Hydrogen adsorption and storage on palladium-decorated graphene with boron dopants and vacancy defects: a first-principles study. Physica E Low Dimens Syst Nanostruct 66:40-47. https://doi.org/10.1016/j. physe.2014.09.022

Madhawan A, Arora A, Das J, Kuila A, Sharma V (2018) Microreactor technology for biodiesel production: a review. Biomass Convers Biorefin 8:485-496. https://doi. org/10.1007/s13399-017-0296-0

Magdesieva TV, Nikitin OM, Zolotukhina EV, Vorotyntsev MA (2014) Palladium nanoparticles-polypyrrole composite as an efficient catalyst for cyanation of aryl halides. Electrochim Acta 122:289-295. https://doi.org/10.1016/j. electacta.2013.09.157

Munnik P, de Jongh PE, de Jong KP (2015) Recent developments in the synthesis of supported catalysts. Chem Rev 115:66876718. https://doi.org/10.1021/cr500486u

Muszynski R, Seger B, Kamat PV (2008) Decorating graphene sheets with gold nanoparticles. J Phys Chem C 112:52635266. https://doi.org/10.1021/jp800977b

Nair AAS, Sundara R, Anitha N (2015) Hydrogen storage performance of palladium nanoparticles decorated graphitic carbon nitride. Int J Hydrog Energy 40:3259-3267. https://doi. org/10.1016/j.ijhydene.2014.12.065

Ncube P, Bingwa N, Baloyi H, Meijboom R (2015) Catalytic activity of palladium and gold dendrimer-encapsulated nanoparticles for methylene blue reduction: a kinetic analysis. Appl Catal A Gen 495:63-71. https://doi.org/10.1016/j. apcata.2015.01.033

Ohara S, Hatakeyama Y, Umetsu M, Sato K, Naka T, Adschiri T (2009) Palladium-polyelectrolyte hybrid nanoparticles for hydrogen sensor in fuel cells. J Power Sources 193:367370. https://doi.org/10.1016/j.jpowsour.2008.11.106

Pang Y, Li Q (2016) A review on kinetic models and corresponding analysis methods for hydrogen storage materials. Int $\mathrm{J}$ Hydrog Energy 41:18072-18087. https://doi.org/10.1016/j. ijhydene.2016.08.018

Reyes-Rios G, García JJ (2012) Alkylation of amines with alcohols catalyzed by palladium nanoparticles. Inorg Chim Acta 392:317-321. https://doi.org/10.1016/j.ica.2012.03.041

Shen C, Wang YJ, Xu JH, Lu YC, Luo GS (2011) Preparation and the hydrogenation performance of a novel catalyst-Pd nanoparticles loaded on glass beads with an egg-shell structure. Chem Eng J 173:226-232. https://doi.org/10.1016/j. cej.2011.07.025

State R, Scurtu M, Miyazaki A, Papa F, Atkinson I, Munteanu C, Balint I (2017) Influence of metal-support interaction on nitrate hydrogenation over $\mathrm{Rh}$ and $\mathrm{Rh}$-cu nanoparticles dispersed on $\mathrm{Al} 2 \mathrm{O} 3$ and $\mathrm{TiO} 2$ supports. Arab J Chem 10:975984. https://doi.org/10.1016/j.arabjc.2017.05.009

Sugawa K, Tahara H, Yamashita A, Otsuki J, Sagara T, Harumoto T, Yanagida S (2015) Refractive index susceptibility of the 
plasmonic palladium nanoparticle: potential as the third plasmonic sensing material. ACS Nano 9:1895-1904

Tanimu A, Jaenicke S, Alhooshani K (2017) Heterogeneous catalysis in continuous flow microreactors: a review of methods and applications. Chem Eng J 327:792-821. https://doi. org/10.1016/j.cej.2017.06.161

Thanh TD, Balamurugan J, Lee SH, Kim NH, Lee JH (2016) Novel porous gold-palladium nanoalloy network-supported graphene as an advanced catalyst for non-enzymatic hydrogen peroxide sensing. Biosens Bioelectron 85:669-678. https://doi.org/10.1016/j.bios.2016.05.075

Viswanathan B (2017) Chapter 10 - Hydrogen Storage. In: Energy sources. Elsevier, Amsterdam, pp 185-212. doi:https://doi. org/10.1016/B978-0-444-56353-8.00010-1

Wojnicki M, Luty-Błocho M, Mech K, Grzonka J, Fitzner K, Kurzydłowski K (2015) Catalytic properties of platinum nanoparticles obtained in a single step simultaneous reduction of Pt(IV) ions and graphene oxide. J Flow Chem 5:2230. https://doi.org/10.1556/JFC-D-14-00032

Wojnicki M, Fitzner K, Luty-Błocho M (2016) Kinetic studies of nucleation and growth of palladium nanoparticles. J Colloid Interface Sci 465:190-199. https://doi.org/10.1016/j. jcis.2015.11.066

Yao X, Zhang Y, Du L, Liu J, Yao J (2015) Review of the applications of microreactors. Renew Sust Energ Rev 47: 519-539. https://doi.org/10.1016/j.rser.2015.03.078

Zhang L, Hessel V, Peng J (2018) Liquid-liquid extraction for the separation of co(II) from $\mathrm{Ni}$ (II) with Cyanex 272 using a pilot scale re-entrance flow microreactor. Chem Eng J 332:131139. https://doi.org/10.1016/j.cej.2017.09.046

Zhao C-X, He L, Qiao SZ, Middelberg APJ (2011) Nanoparticle synthesis in microreactors. Chem Eng Sci 66:1463-1479 